\title{
Effect of Polymer Brush Architecture on Antibiofouling Properties
}

\author{
Gesine Gunkel, ${ }^{\dagger}$ Marie Weinhart, ${ }^{\ddagger}$ Tobias Becherer, ${ }^{\ddagger}$ Rainer Haag, ${ }^{\ddagger}$ and Wilhelm T. S. Huck ${ }^{*},, \S$ \\ ${ }^{\dagger}$ Melville Laboratory for Polymer Synthesis, Department of Chemistry, University of Cambridge, Lensfield Road, Cambridge, \\ CB21EW, U.K. \\ ${ }^{\ddagger}$ Institut für Chemie und Biochemie, Freie Universität Berlin, Takustr. 3, 14195 Berlin, Germany \\ ${ }^{\S}$ Institute for Molecules and Materials, Radboud University Nijmegen, Heyendaalseweg 135, 6525 AJ Nijmegen, The Netherlands
}

\section{Supporting Information}

ABSTRACT: Polymer brushes show great promise in nextgeneration antibiofouling surfaces. Here, we have studied the influence of polymer brush architecture on protein resistance. By carefully optimizing reaction conditions, we were able to polymerize oligoglycerol-based brushes with sterically demanding linear or dendronized side chains on gold surfaces. Protein adsorption from serum and plasma was analyzed by surface plasmon resonance. Our findings reveal a pronounced dependence of biofouling on brush architecture. Bulky yet

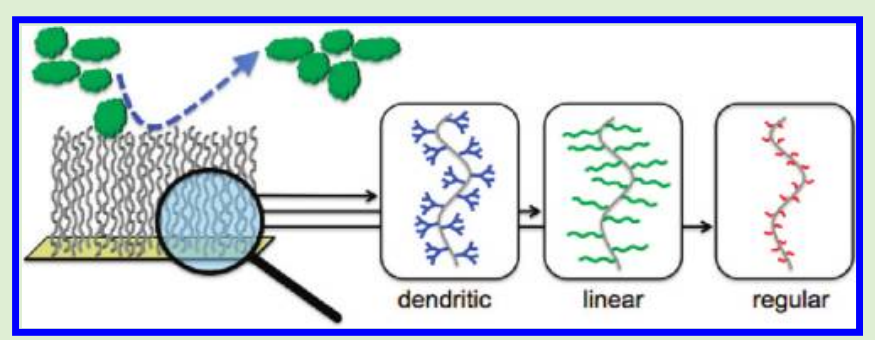
flexible side chains as in dendronized brushes provide an ideal environment to repel protein-possibly through formation of a hydration layer, which can be further enhanced by presenting free hydroxyl groups on the polymer brushes. A deeper understanding of how brush architecture influences protein resistance will ultimately enable fabrication of surface coatings tailored to specific requirements in biomedical applications.

\section{INTRODUCTION}

Polymer brushes are widely explored as next-generation antifouling surfaces ${ }^{1}$ because parameters such as thickness, grafting density, and side-chain structures can be easily tuned and adjusted to specific needs. The wide spectrum of polymers explored today illustrates the demand of protein resistant surface coatings for applications at the interface of engineering, biology, and medicine. ${ }^{2-4}$ So far, research efforts focused on the identification of polymer brushes with superior characteristics, and there is a lack in understanding of how chemical and structural characteristics determine antifouling properties. Studies on poly(oligoethylene glycol methacrylate) (POEGMA) brushes with different side-chain lengths indicated that side-chain architecture indeed influences protein resistance. ${ }^{5-7}$ Recent theoretical work pointed out that better surface coverage through increased polymer density enhances protein resistance. ${ }^{8}$ However, the effect of brush architecture on antifouling properties appears to be more complex, as some brushes with small side chains repel proteins, too. ${ }^{9-11}$ Pioneering screenings with self-assembled monolayers (SAMs) identified structural criteria for good protein resistance such as flexible packing, the ability of water to penetrate the SAM, polar functional groups, no net charge, and the presence of hydrogen bond acceptors but not donors. ${ }^{12-14}$ Currently poly(ethylene glycol) (PEG) is frequently used for antibiofouling surface coatings, ${ }^{15}$ but the relatively low stability toward oxidation limits its application in biological systems. Polyglycerol, a comparable biocompatible aliphatic polyether, shows higher stability toward oxidation, ${ }^{16}$ and SAMs presenting oligoor polyglycerols exhibit excellent protein resistance. ${ }^{17-19}$
Moreover, glycerol-based polymers in contrast to ethylene glycol-based polymers allow an easy access to branched architectures, which make polyglycerols an ideal system to investigate different architectures.

In this study, we aim to elucidate the relation between the polymer brush architecture and its antifouling properties, which aims at facilitating the design and synthesis of "custom-made" brushes for specific applications. Dendritic monomers of generation 1 and 2, linear macromonomers based on oligoglycerol derivatives, and a glycerol monomer were synthesized and polymerized via surface-initiated ATRP $^{20}$ to yield the corresponding brushes illustrated in Scheme 1. Antifouling properties of these modified surfaces were studied by surface plasmon resonance (SPR) with biological media and single-protein solutions.

\section{RESULTS AND DISCUSSION}

Polymer brushes were synthesized with five different monomers, all incorporating a glycerol motif. Thanks to the three hydroxyl groups in glycerol, a variety of different structures are accessible. In this study, dendritic monomers of generations 1 and 2 were synthesized as well as linear hydroxylated and methoxylated oligoglycerol macromonomers. Core hydroxylated dendrons were synthesized according to the literature, ${ }^{21}$ and the polymerizable moiety was incorporated by subsequent coupling of the core hydroxyl group with acrylic

Received: July 7, 2011

Revised: August 29, 2011

Published: September 20, 2011 
Scheme 1. Chemical Structures (top) of the Glycerol-Based Brushes Synthesized (from left to right): Dendritic Glycerol Acrylate Brushes of Generation 1 and $2(1,2)$, Linear Oligo(methyl glycerol) Methacrylate (3) and Linear Oligoglycerol Methacrylate (4) Brushes, and Regular Glycerol Monomethacrylate Brushes (5) as Well as Schematic Illustrations of the Resulting Brush Architectues (bottom)

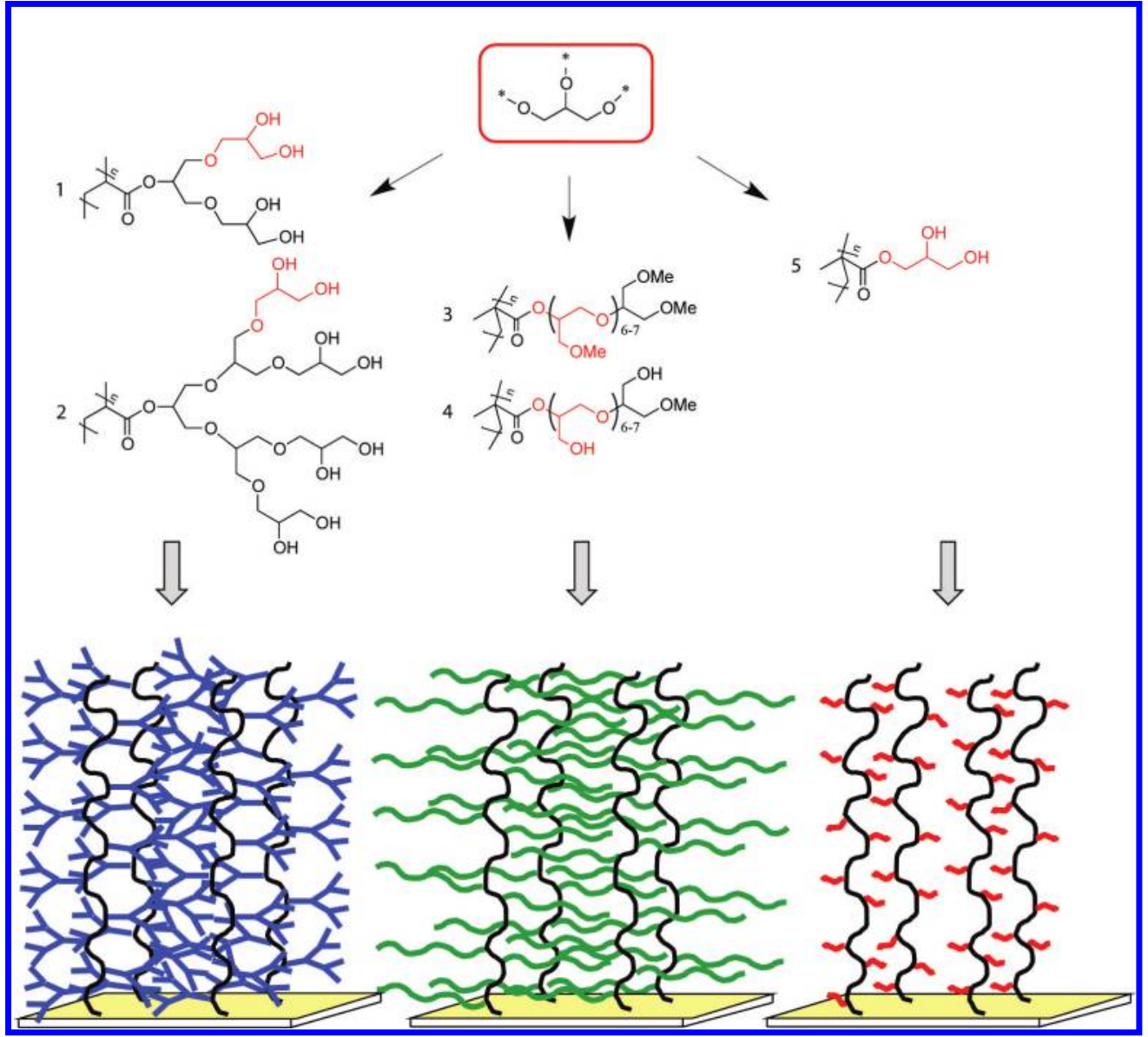

Table 1. Structural Characteristics of the Polymer Brushes: Swelling Factors in PBS, Captive Bubble Contact Angles, Rms Surface Roughness, and Main IR Vibrations

\begin{tabular}{|c|c|c|c|c|c|c|}
\hline \multirow[b]{2}{*}{ brush } & \multirow[b]{2}{*}{ swelling factor } & \multirow[b]{2}{*}{ contact angle $[\mathrm{deg}]$} & \multirow[b]{2}{*}{ surface roughness $[\mathrm{nm}]$} & \multicolumn{3}{|c|}{ IR vibrations $\left[\mathrm{cm}^{-1}\right]^{a}$} \\
\hline & & & & $v_{\text {RCOOR }}$ & $v_{\text {prim } / \mathrm{sec} \mathrm{OH}}, v_{\mathrm{COC}}$ & $v_{\text {OMe }}$ \\
\hline 1 & $3.4 \pm 1.1$ & $49 \pm 7$ & $1.4 \pm 0.3$ & 1735 & $1256-1062$ & \\
\hline 2 & n.d. ${ }^{b}$ & $52 \pm 4$ & $1.8 \pm 0.2$ & 1728 & $1254-1088$ & \\
\hline 3 & $3.1 \pm 0.6$ & $54 \pm 5$ & $2.2 \pm 0.1$ & 1730 & 1124 & 1464 \\
\hline 4 & $3.5 \pm 1.4$ & $42 \pm 6$ & $2.0 \pm 0.3$ & 1719 & $1144-1091$ & 1465 \\
\hline 5 & $2.8 \pm 0.4$ & $44 \pm 5$ & $1.2 \pm 0.2$ & 1732 & 1172,1048 & \\
\hline
\end{tabular}

acid chloride. Linear macromonomers were synthesized from linear monohydroxylated oligo(methyl glycerol) and oligo(ethoxy ethyl glycerol) and methacryloyl chloride. ${ }^{19,22}$ Careful acidic treatment of acetal protected monomers yielded the corresponding monomers with free hydroxyl groups (all details of macromonomer synthesis are described in the Supporting Information). The resulting dendritic $(\mathbf{1}, 2)$ and bottle brushes $(3,4)$ were compared to a regular glycerol monomethacrylate brush (5) with a small side chain (Scheme 1). All brushes were synthesized by surface-initiated ATRP on gold deposited on silicon wafers and on SPR sensor chips via an immobilized thiol-functionalized initiator. ${ }^{23}$ Polymerizations were accomplished in custom-made sample holders to reduce the volume to ca. $200 \mu \mathrm{L}$ polymerization solution per sample. The polymerization conditions, catalyst, and solvent were optimized for each monomer (full experimental details in the Supporting Information). Analysis by ATR-FTIR spectroscopy revealed the main bands of ester, hydroxyl, methoxy, and ether groups (see Table 1) and confirmed the presence of the brushes. Besides, the dry thickness was measured by ellipsometry, which also underlines successful ATRP. To study homogeneity, the rms roughness of the brushes was determined by AFM. The roughness lies between 1.2 and $2.2 \mathrm{~nm}$ (Table 1, AFM images in Supporting Information). In addition, the swelling factors of the brushes in phosphate buffered saline (PBS) were determined by wet ellipsometry measurements, resembling conditions during the SPR measurement, where the brush is swollen in PBS. All brushes exhibit swelling factors around 3 
(Table 1). Minor differences stem from a dependency of the swelling factor on the thickness. Moreover, the wettability of these surfaces was studied, as the hydrophilicity is an important factor for antifouling properties. Contact angles were determined using the captive bubble method. ${ }^{24}$ Notably, the contact angles of all types of brushes are clustered around $45^{\circ}-$ $50^{\circ}$ (see Table 1), indicating that their hydrophilicity is similar.

Antifouling properties of the brushes were studied by surface plasmon resonance, a well-established technique frequently employed for adsorption studies. ${ }^{25}$ To compare the results with other published data, SPR measurements were performed with frequently used single protein solutions $(1 \mathrm{mg} / \mathrm{mL}$ fibrinogen or bovine serum albumin in PBS). Interestingly, all brushes are good surface coatings under these conditions (Table 2), which

Table 2. Adsorption of Fibrinogen, Bovine Serum Albumin, Human Serum, and Plasma in $\mathrm{ng} / \mathrm{cm}^{2}$ to the Polymer Brush Modified Surfaces

\begin{tabular}{lcccc} 
brush & $\begin{array}{c}\text { human } \\
\text { serum }\end{array}$ & $\begin{array}{c}\text { human blood } \\
\text { plasma }\end{array}$ & $\begin{array}{c}\text { bovine serum } \\
\text { albumin }\end{array}$ \\
1 & $35 \pm 17$ & $24 \pm 17$ & $7 \pm 5$ & $4 \pm 4$ \\
2 & $103 \pm 14$ & $71 \pm 7$ & $24 \pm 9$ & $7 \pm 4$ \\
3 & $116 \pm 16$ & $69 \pm 9$ & $2 \pm 2$ & $12 \pm 4$ \\
4 & $56 \pm 6$ & $51 \pm 5$ & $9 \pm 3$ & $18 \pm 4$ \\
5 & $130 \pm 4$ & $62 \pm 4$ & $2 \pm 1$ & $0 \pm 0$ \\
POEGMA & $40 \pm 5$ & $29 \pm 4$ & $3 \pm 2$ & $6 \pm 2$ \\
\hline
\end{tabular}

suggests that studying antifouling properties solely with solutions of single proteins is not sufficient to test applications in biomedical systems. This is supported by a previous study that showed that the superior performance of brushes can only be detected under ambitious physiological conditions. ${ }^{10}$

Hence, the brushes were challenged with nondiluted human serum and human blood plasma, as they mimic applications in biological systems, where surfaces are in contact with e.g. blood or cells. As can be seen from the data illustrated in Figure 1, a pronounced dependence of protein adsorption on the brush architecture is observed. Both serum and plasma reveal a comparable trend. The best performance is achieved with dendritic brush 1 , which adsorbs only around $35 \mathrm{ng} / \mathrm{cm}^{2}$ of human serum. This value is as good as the current standard for antibiofouling surfaces, POEGMA brushes (Table 2); only some brushes with zwitterionic and hydroxylated side-chains have been reported to show even lower adsorption. ${ }^{11,26,27}$ Slightly higher adsorption is detected on linear hydroxylated oligoglycerol-based brush 4, followed by higher generation dendritic brush 2 and linear methylated oligoglycerol-based brush 3. The highest adsorption of serum (ca. $130 \mathrm{ng} / \mathrm{cm}^{2}$ ) is observed on poly(glycerol monomethacrylate) brush 5 . These findings suggest the importance of brush architecture and show that brushes with dendritic side chains are superior to brushes with linear or short side chains. Notably, generation 2 dendritic brushes of only $3 \mathrm{~nm}$ dry thickness already show a reasonably good protein resistance. The surface-initiated polymerization of such bulky dendritic monomers becomes increasingly difficult due to steric hindrance and shielding of the growing chain end. ${ }^{28}$ However, at thicknesses where brushes with small side chains are not resistant yet, ${ }^{27,29}$ the brushes with dendritic side chains show low protein adsorption. In comparison to linear or short side chains, dendritic side chains offer a route to locally increase the polymer density. The backbones of dendronized polymers are typically stiffer than others because they are more

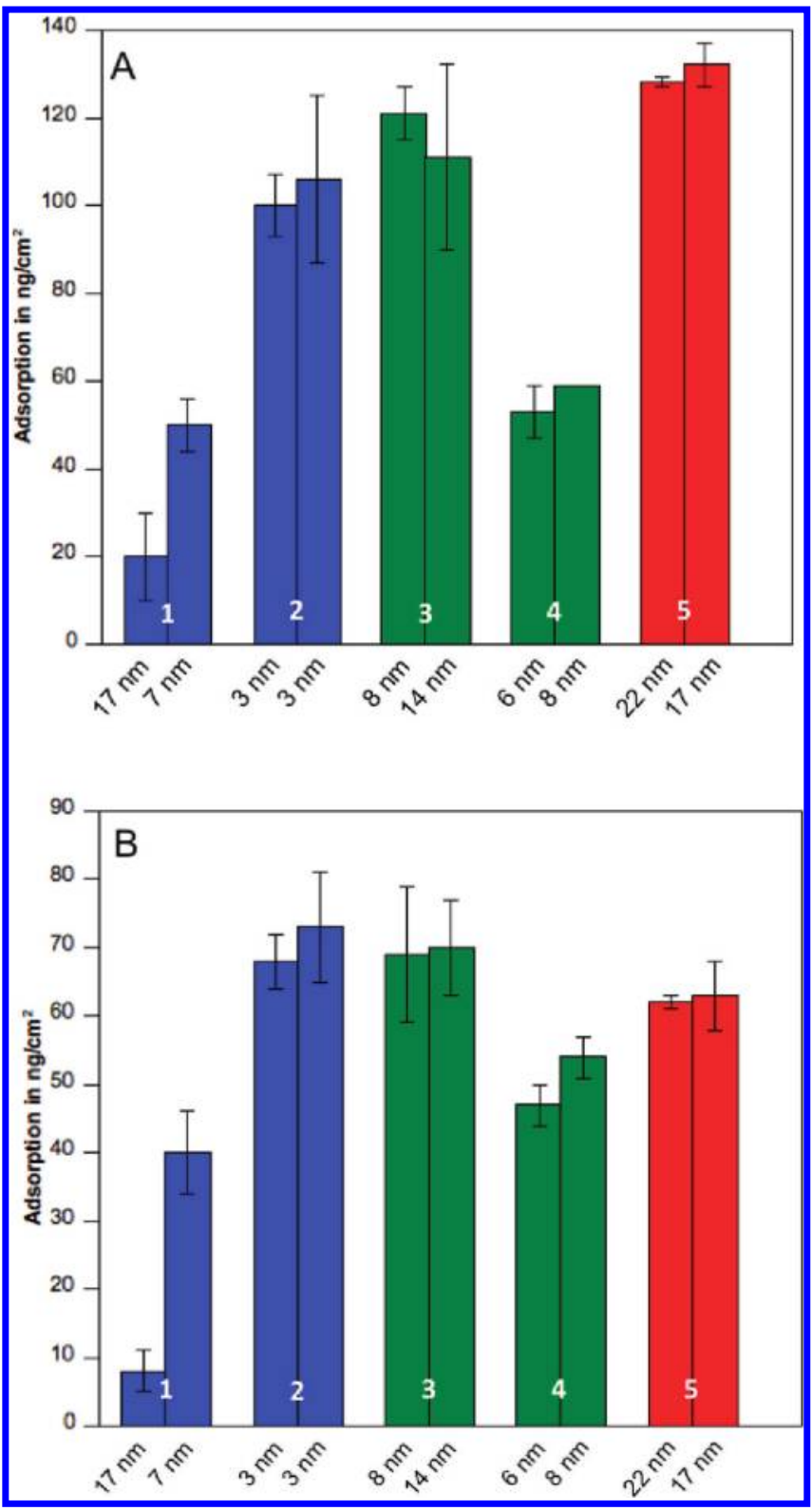

Figure 1. SPR results showing the adsorption of (A) nondiluted human serum and (B) nondiluted human blood plasma in $\mathrm{ng} / \mathrm{cm}^{2}$ to dendritic brushes 1 and 2, bottle brushes 3 and 4 , and regular brush 5 (dry thickness in $\mathrm{nm}$ given below).

stretched in order to generate space of the bulky side chains. ${ }^{8,30}$ A relationship between polymer chain flexibility, packing density, and increased protein resistance has been discussed recently. ${ }^{31,32}$ These features facilitate penetration of water into the brush and the formation of a hydration layer. The energy barrier that has to be overcome to disrupt the hydration makes the binding of proteins energetically less favorable, which is considered to play a major role in preventing biofouling. ${ }^{13,32-34}$ Furthermore, the antifouling results obtained here positively correlate with the swelling factors (Table 1), indicating better penetration of water mediated by hydroxyl groups. The effect of hydroxyl groups becomes obvious by comparing the two linear brushes 3 and 4 . Despite similar structures, 3 has methoxy-terminated side chains while $\mathbf{4}$ has free hydroxyl groups. This change to hydroxyl groups leads to a $50 \%$ reduction of serum adsorption. These findings underline the 
importance of the formation of a tightly bound hydration layer for antifouling properties and how this can be supported by hydroxyl groups. Studies with unprotected carbohydrate (exhibiting free hydroxyl groups) SAMs and brushes are in agreement with our findings, ${ }^{35-37}$ although they challenge the long-held view that hydrogen bond donors act detrimental. ${ }^{12}$

\section{CONCLUSIONS}

We successfully synthesized novel polymer brushes with sterically demanding side chains based on oligoglycerols. The brushes were characterized via ATR-FTIR spectroscopy, AFM, dry and wet ellipsometry, and captive bubble contact angles. Protein resistance of these surfaces was studied by surface plasmon resonance. We identified that the nonfouling properties of surfaces are influenced by brush architecures, which in turn are determined by the side-chain structure of the macromonomers. Our results show superior performance of dendritic and bottle brushes based on oligoglycerol when tested with demanding biological media like undiluted serum or blood plasma. However, the brushes need to be of a sufficient thickness, which can be synthetically challenging, and therefore we were limited in our studies into the degree of branching of the monomer. Furthermore, we noted that only complex media, but not single protein solutions, provide stringent enough test conditions for our brushes, as even the inferior regular brushes show good resistance to solutions of fibrinogen and bovine serum albumin alone. This supports the findings that brushes offer better nonfouling properties than SAMs, ${ }^{10}$ as they already show incomplete resistance to single protein solutions. The insights presented here can help in the design of an ideal protein-resistant surface coating. In addition to the brush architecture, other parameters should be considered due to the complex nature of biofouling processes. Factors such as functional groups of the monomer, wettability, homogeneity, and the composition of the biological media used need to be taken into account when designing antibiofouling surface coatings. These aspects will be the subject of future research.

\section{ASSOCIATED CONTENT}

\section{S Supporting Information}

Full experimental details, AFM images of polymer brush-coated surfaces, and additional SPR data. This material is available free of charge via the Internet at http://pubs.acs.org.

\section{AUTHOR INFORMATION}

\section{Corresponding Author}

*E-mail: wtsh2@cam.ac.uk.

\section{ACKNOWLEDGMENTS}

G.G. acknowledges the Gottlieb Daimler and Karl Benz Foundation for funding. Dr. J. Bünsow is thanked for helpful discussions and J. Vonnemann for technical assistance.

\section{REFERENCES}

(1) Banerjee, I.; Pangule, R. C.; Kane, R. S. Adv. Mater. 2011, 23, 690-718.

(2) Gautrot, J. E.; Trappmann, B.; Oceguera-Yanez, F.; Connelly, J.; He, X.; Watt, F. M.; Huck, W. T. S. Biomaterials 2010, 31, 5030-5041.

(3) Cheng, G.; Xue, H.; Zhang, Z.; Chen, S.; Jiang, S. Angew. Chem., Int. Ed. 2008, 47, 8831-8834.

(4) Welch, M.; Rastogi, A.; Ober, C. Soft Matter 2011, 7, 297-302.

(5) Brown, A. A.; Khan, N. S.; Steinbock, L.; Huck, W. T. S. Eur. Polym. J. 2005, 41, 1757-1765.
(6) Kizhakkedathu, J. N.; Janzen, J.; Le, Y.; Kainthan, R. K.; Brooks, D. E. Langmuir 2009, 25, 3794-3801.

(7) Ma, H.; Hyun, J.; Stiller, P.; Chilkoti, A. Adv. Mater. 2004, 16, 338-341.

(8) de Vos, W. M.; Leermakers, F. A. M.; Lindhoud, S.; Prescott, S. W. Macromolecules 2011, 44, 2334-2342.

(9) Rodriguez Emmenegger, C.; Brynda, E.; Riedel, T.; Sedlakova, Z.; Houska, M.; Alles, A. B. Langmuir 2009, 25, 6328-6333.

(10) Ladd, J.; Zhang, Z.; Chen, S.; Hower, J. C.; Jiang, S. Biomacromolecules 2008, 9, 1357-1361.

(11) Rodriguez-Emmenegger, C.; Brynda, E.; Riedel, T.; Houska, M.; Subr, V.; Alles, A. B.; Hasan, E.; Gautrot, J. E.; Huck, W. T. S. Macromol. Rapid Commun. 2011, 32, 952-957.

(12) Chapman, R. G.; Ostuni, E.; Takayama, S.; Holmlin, R. E.; Yan, L.; Whitesides, G. M. J. Am. Chem. Soc. 2000, 122, 8303-8304.

(13) Herrwerth, S.; Eck, W.; Reinhardt, S.; Grunze, M. J. Am. Chem. Soc. 2003, 125, 9359-9366.

(14) Ostuni, E.; Chapman, R. G.; Holmlin, R. E.; Takayama, S.; Whitesides, G. M. Langmuir 2001, 17, 5605-5620.

(15) Mrksich, M.; Whitesides, G. M. In Poly(ethylene glycol); Harris, J. M., Zalipsky, S., Eds.; American Chemical Society: Washington, DC, 1997; Vol. 680, pp 361-373.

(16) Siegers, C.; Biesalski, M.; Haag, R. Chem.-Eur. J. 2004, 10, $2831-2838$

(17) Wyszogrodzka, M.; Haag, R. Langmuir 2009, 25, 5703-5712.

(18) Wyszogrodzka, M.; Haag, R. Biomacromolecules 2009, 10, 1043-1054.

(19) Weinhart, M.; Grunwald, I.; Wyszogrodzka, M.; Gaetjen, L.; Hartwig, A.; Haag, R. Chem.-Asian J. 2010, 5, 1992-2000.

(20) Jones, D. M.; Huck, W. T. S. Adv. Mater. 2001, 13, 1256-1259.

(21) Wyszogrodzka, M.; Haag, R. Chem.-Eur. J. 2008, 14, 92029214

(22) Weinhart, M.; Becherer, T.; Haag, R. Chem. Commun. 2011, 47, $1553-1555$.

(23) Jones, D. M.; Brown, A. A.; Huck, W. T. S. Langmuir 2002, 18, $1265-1269$.

(24) Jonas, A. M.; Glinel, K.; Oren, R.; Nysten, B.; Huck, W. T. S. Macromolecules 2007, 40, 4403-4405.

(25) Mrksich, M.; Sigal, G. B.; Whitesides, G. M. Langmuir 1995, 11, $4383-4385$.

(26) Jiang, S.; Cao, Z. Adv. Mater. 2010, 22, 920-932.

(27) Zhao, C.; Li, L.; Wang, Q.; Yu, Q.; Zheng, J. Langmuir 2011, 27, 4906-4913.

(28) Chen, Y.; Xiong, X. Chem. Commun. 2010, 46, 5049-5060.

(29) Yang, W.; Xue, H.; Li, W.; Zhang, J.; Jiang, S. Langmuir 2009, 25, 11911-11916.

(30) Guo, Y.; van Beek, J. D.; Zhang, B.; Colussi, M.; Walde, P.; Zhang, A.; Kröger, M.; Halperin, A.; Dieter Schlüter, A. J. Am. Chem. Soc. 2009, 131, 11841-11854.

(31) Chang, Y.; Shih, Y.-J.; Ko, C.-Y.; Jhong, J.-F.; Liu, Y.-L.; Wei, T.C. Langmuir 2011, 27, 5445-5455.

(32) Chen, S.; Li, L.; Zhao, C.; Zheng, J. Polymer 2010, 51, 52835293.

(33) Hower, J. C.; Bernards, M. T.; Chen, S.; Tsao, H.-K.; Sheng, Y.J.; Jiang, S. J. Phys. Chem. B 2008, 113, 197-201.

(34) Shao, Q.; He, Y.; White, A. D.; Jiang, S. J. Phys. Chem. B 2010, 114, 16625-16631.

(35) Metzke, M.; Guan, Z. Biomacromolecules 2008, 9, 208-215.

(36) Luk, Y.-Y.; Kato, M.; Mrksich, M. Langmuir 2000, 16, 96049608.

(37) Yu, K.; Kizhakkedathu, J. N. Biomacromolecules 2010, 11, 30733085 . 